\title{
¿S Research Square

\section{JUNTS framework for creating web apps to bridge the gap in doctor-patient communication: the case of COMjuntos application in the field of rare diseases}

\section{Rosa Estopà i Bagò}

Universitat Pompeu Fabra Facultat de Traduccio i Interpretacio

Manuel Armayones Ruiz ( $\nabla$ marmayones@uoc.edu )

Universitat Oberta de Catalunya https://orcid.org/0000-0001-6345-8711

\section{Research}

Keywords: health literacy, medical communication, medical apps, medical language, rare diseases, doctor-patient communication

Posted Date: September 29th, 2020

DOI: https://doi.org/10.21203/rs.2.23480/v3

License: (c) (1) This work is licensed under a Creative Commons Attribution 4.0 International License. Read Full License 


\section{Abstract}

\section{Background.}

The diagnosis or even the suspicion of a disease on their children has an emotional impact on their parents and generates a need to acquire relevant knowledge and skills in a short period of time. For a range of motives, these parents will sometimes face communicative and cognitive barriers in their communication with the professionals that care for their children. These barriers can have a negative effect on knowledge acquisition, treatment adherence and, more generally, affect their relationship with clinicians. To overcome these barriers, we developed JUNTS framework following three steps: carrying out 10 semi-structured interviews with parents of child's affected by a rare disease. Secondly, we carried out interviews with health professionals and patient's organization staff. The third and last steep was to organize a meeting of the whole research team and patient's association staff of Spanish Federation of Rare Disease and list a set of design trends that could help parents to solve the main communicational and linguistic barriers.

\section{Results.}

The JUNTS Framework presented here helps parents manage the communicative situations they find themselves in the relationship with health professionals, by exploiting a polyphonic design that includes different levels of involvement. One of the characteristics that makes this approach particularly unique is that parents and representatives of patient-support associations work jointly with health professionals, psychologists and language experts in designing the contents of a parents-support application. The Framework exploits a modular structure centred around a series of short challenges with different types of user involvement (visual, textual and hypertextual). For optimal adherence and to ensure patients complete the whole route through the support material, elements of persuasive design have been integrated.

\section{Conclusions.}

In this paper, we outline how the JUNTS framework has been designed and used to develop the web app COMjuntos based in JUNTS framework. This web app facilitates medical communication and has been specifically designed to help parents who have a child with a rare disease empower themselves in the main communicative situations with health professionals. The JUNTS framework can be adapted to any other type of chronic disease or condition.

\section{Background}

The diagnosis, or even the suspicion, of a chronic disease makes patients aware of their need to acquire both the knowledge and competences that will ensure they develop the highest possible degree of selfcare and autonomy in the management of their disease (1). Equally, many patients can find it extremely challenging to put questions to a specialist about a given medical test, diagnosis or treatment that is 
unclear to them. In such circumstances, patients face a series of physical, linguistic and psychological barriers that in many cases will determine how successfully they are able to adhere to their therapeutic regimen and comply with their medical prescriptions (2).

The doctor-patient communication is of great importance and is closely related, for example, with adherence to treatment. The factors that affect this communication are multidimensional and include aspects related both to health systems and, at a more individual level, to escalating patient demand, staffing problems, and a lack of empathy and personalised care. In contrast, among the factors that can enhance communication is the medical attention that takes into account patients' beliefs, needs and preferences, and which, therefore, is more carefully tailored to the individual (3).

Doctor-patient communication is especially complex because it is an asymmetric relationship and often too unidirectional: the clinician is the one with the knowledge about the disease and the power to help, treat and cure the patient; moreover, the doctor controls the space in which the communicative acts are played out, since it forms part of her workplace. In contrast, the patient, as the non-expert finds himself in a very vulnerable situation, involved in a communicative act about a health problem and, with little understanding of his illness, he may well feel afraid, confused and even embarrassed, while perceiving the hospital space to be hostile. These communicative acts may be oral and, therefore, ephemeral medical visits, tests, consultations, etc. - but may also be written - medical reports, a patient's informed consent, treatment plans, etc. - . And written acts are permanent and can be consulted by the patient in their own home (4).

In the case of rare diseases, that is, those that affect less than one in 10,000 people, and which are calculated to number around seven thousand (5), patients face a situation in which effective doctorpatient communication acquires a central role. Here, health professionals can generate a climate of trust and confidence in their patients, by providing clinical care and by correctly addressing the patients' needs for information and knowledge. Moreover, in the case of rare diseases such communicative acts are especially frequent (given the chronic nature of these disorders) and so they come to form the basis of an appropriate level of empowerment of patients and their families (6).

The communicative acts involving patients and health professionals are threatened by the difficulty that patients and their relatives have in understanding the messages that the professionals wish to transmit. In the case of paediatric rare diseases affecting children, this problem is often exacerbated as parents and clinician involvement tends to be even more intense (7). These demands, however, can clash with difficulties related to both the complexity of the diseases and the pressures of care, the lack of knowledge and the time professionals have available to dedicate to parents (6).

In addition to the importance of communicative acts in treating chronic illnesses, in general, and rare diseases, in particular, the level of the family's health literacy is critical for their empowerment and for ensuring they acquire a perception of control in managing the medical condition and its psychological and social impacts (8). Here, we understand health literacy as the capacity, motivation and competence to "access, understand, appraise, and apply health information in order to make judgments and take 
decisions in everyday life concerning healthcare, disease prevention and health promotion to maintain or improve quality of life during the life course" (9).

Adequate health literacy is fundamental in the correct management of complex disorders such as rare diseases and is one of the challenges that must be successfully faced in order to improve the quality of life of patients and their families (10). In this regard, an equally important challenge is that of identifying and minimizing the cognitive interferences that can be transmitted via the language and, especially, the terminology used by professionals. In the specific case of paediatric rare diseases, the medical-parents communication must be based in trust and this trust can be affected by communicational and cognitive interferences (11)

Low levels of health literacy can also lead to difficulties in accessing the requisite healthcare, understanding the information provided by health professionals, and adhering to treatments, and can, in turn, result in an increased number of hospital admissions and visits to A\&E departments and family doctors. For example, the use of communicative and linguistic strategies that facilitate comprehension helps patients gain a better understanding of the information that clinicians seek to convey to them in written texts. These strategies can usefully include: a) using simple and appropriate syntax, b) employing explicit pragmatic connectors to facilitate the interpretation of information, c) explaining semantically opaque terminology, d) defining all acronyms and abbreviations, e) ensuring that the punctuation used facilitates interpretation and f) using metaphors to clarify complex ideas, etc. In addition, when presenting the information, the use of colour codes, images, videos, etc. is recommended to boost comprehension and, in this way, people can become more health literate and the barriers between doctors and patients can be removed (11).

To overcome the problems described above, we present both a framework (JUNTS in advance) and a first web app application COMjuntos (COMjuntos in advance), that serves to guide parents in their communication with health professionals. COMjuntos is recommended by Spanish Federation of Rare Diseases (FEDER in advance) and is linked in their website (www.enfermedades-raras.org).

This paper has two main objectives. First, it presents the JUNTS. Second, it describes COMjuntos, based in JUNTS to a specific case: common trends of rare paediatric diseases. The COMjuntos aims to help parents with a child affected by a rare disease to cope with the main communicative situations they find themselves in when engaging with health professionals. The aim is not to provide knowledge about a specific illness, in this case rare diseases, but to anticipate the obstacles that may arise in the communication with clinicians and to provide parents with the strategies that enable them to feel empowered and to manage the day-to-day problems they face in dealing with their child's illness.

By describing the JUNTS and its application in the design of COMjuntos, we seek to make available to researchers a framework that can be used in relation with any other type of chronic condition or disease.

In our work we will describe COMjuntos in Results section, like the first results of the JUNTS framework which methodology and its application we describe in Methods section. We consider that offering first a 
real result a mobile app currently in service and available in Apple Store and Google Play can help to understand the underlying assumption and principles with we have been working on

\section{Results}

\section{The web app COMjuntos: an example of application of JUNTS framework:}

We aware that to describe a framework represent an abstraction itself. To help scientist to understand our framework design following we will offer a specific product created following the JUNTS: COMjuntos

COMjuntos is the outcome of a RECERCAIXA and ACUP research project carried out in conjunction with the Spanish Federation of Rare Diseases (FEDER) and with the technical support of healthcare professionals at the Vall d'Hebron Hospital in Barcelona. Linguists and psychologists worked alongside educational psychologists - experts in learning design - to develop an application that promotes family health literacy. The app provides content endorsed by health professionals (specifically, doctors and psychologists) and combines the use of controlled language with linguistic strategies adapted to the nonexpert to facilitate understanding. COMjuntos was launched in 2018 and application is available in their 1.3 version (launched in June 2020) in different formats:

1. In a downloadable app format for both IOS and Android devices

2. In web format: http://appCOMJUNTOS.es/

3. In book format, both printed and as a downloadable pdf: http://appCOMjuntos.es/wpcontent/uploads/2018/11/ES-libro-COMJUNTOS.pdf

All versions of COMjuntos are available in open source ensuring they are accessible to the entire target population.

\section{Application of the patient-centred design principle to COMjuntos}

In the case of COMjuntos, to "understand the user", we conducted ten in-depth interviews between January and June of 2017 in Hospital de la Vall d'Hebron and in the facilities of the Spanish Federation of Rare Diseases in Barcelona (12). Later, various working meetings were held with experts and representatives of FEDER associations, in which, in addition to contributing to content creation based on their personal experience, participants were asked for feedback on the contents being developed.

Likewise, to "observe how users interact with the prototype", different versions of the first prototypes of COMjuntos were tested, both by the experts (who had, in fact, participated in their design) and by parents and representatives of rare disease associations. Specifically, they came from Spanish Association of Lowe Syndrome, Spanish Association for Lysosomal-Acid-Lipase, Association for Syndrome STXBP1, Spanish Association of Prader-Willi Syndrome, Spanish Association of Mucopolysaccharidosis. All of the participants were asked (video recorded in mobile app COMjuntos) to ask some specific general questions (not specifically about the disease of their kids) about: the first moment and feelings about 
diagnostic, how to manage the situation, how they prepare doctor test, what they would say to a "novel" parent about the role of the association, if they understand the medical report and how they act when they have doubts, how they use the ICT to manage their kids disease.

\section{Application of persuasive design to COMjuntos}

In designing COMjuntos, a first prospective analysis was carried out in which, based on the principles of the Persuasive Systems Design model developed by Oinas-kukkonen (13), elements of this model were incorporated to increase the degree of persuasiveness of our application, with the aim of encouraging parents to use it (14). Some of the more relevant elements included a modular design based on challenges to facilitate the consultation of information, the use of colour codes (see Figure 1) to simplify even further the information and the use of fonts of different sizes and formats to help distinguish between basic and more specific information.

Another persuasive element employed was that of the principle of authority (the PSD Authority Principle), achieved via the participation in the videos of the Vall d'Hebron Hospital doctors and researchers, internationally recognized teams specialising in minority diseases, psychologists and members of the FEDER board, together with the parents of the affected children. They recommend appropriate ways of proceeding and suggest certain strategies in their role as experienced witnesses (the PSD Suggestion Principle).

Finally, the language of the content was analysed to ensure COMjuntos and, above all, the modular structure of the application was appropriately simplified and readily understandable (PSD Reduction Principle).

We deemed it important that COMjuntos be made up of various modules that would help structure knowledge and the situations in which the patient might find themselves in real life. These modules, although they follow a certain chronological logic, do not need to be consulted in a linear fashion. Thus, the narrative thread of the COMjuntos app comprises five communicative acts that invite families to overcome certain situations they might find themselves in when having to communicate with a health professional. Adhering to the Reduction Principle, each module and all its contents are given a colour, as shown in Figure 1. Thus, green is assigned to Tenemos una enfermedad rara en la familia [We have a rare disease in the family]; yellow to Cómo preparar una visita médica [How to prepare a medical visit]; brown to Recibimos un informe médico [We have received a medical report]; red to Tenemos una prueba médica [We have a medical test] and, finally, purple to ¿Qué más puedo aprender? [What else can I learn?].

In turn, the different communicative situations are structured around a series of Challenges as shown in Table 2. 


\begin{tabular}{|c|c|}
\hline Communicative situation & Challenge \\
\hline $\begin{array}{l}\text { - We have a rare disease in the family } \\
\text { The day the doctor communicates to the parents the diagnosis or possible diagnosis } \\
\text { of their child }\end{array}$ & $\begin{array}{l}\text { Challenge } 1 \\
\text { What is a rare disease? }\end{array}$ \\
\hline $\begin{array}{l}\text { - How should we prepare ourselves for the medical visit? } \\
\text { When the family has a doctor's visit }\end{array}$ & $\begin{array}{l}\text { Challenge } 2 \\
\text { What do we want to achieve during the medical } \\
\text { visit? } \\
\text { Challenge } 3 \\
\text { What can we do during and after the medical visit? }\end{array}$ \\
\hline $\begin{array}{l}\text { - We have received a medical report } \\
\text { When a clinician gives you a written medical report }\end{array}$ & $\begin{array}{l}\text { Challenge } 4 \\
\text { What can we do to understand a medical report } \\
\text { correctly? }\end{array}$ \\
\hline $\begin{array}{l}\text { - We have a medical test } \\
\text { When your child must have a medical test }\end{array}$ & $\begin{array}{l}\text { Challenge } 5 \\
\text { What to ask the doctor when he sends your child for } \\
\text { a test? } \\
\text { Challenge } 6 \\
\text { How to prepare your child for tests? }\end{array}$ \\
\hline $\begin{array}{l}\text {-What else can I learn? } \\
\text { When we do not know what else can be done }\end{array}$ & $\begin{array}{l}\text { Challenge } 7 \\
\text { How can I learn from other families? }\end{array}$ \\
\hline
\end{tabular}

Table 2: COMjuntos communicative situations and challenges

\section{Application of the polyphonic design to COMjuntos}

Each of the seven challenges comprises: a) a video with real testimonies from affected families and health professionals specializing in rare diseases (paediatricians, doctors, geneticists, etc.), b) a hypertext that explains the situation and anticipates the doubts that usually arise, c) a basic dictionary of medical terms designed for non-experts and d) information including tips and links to resources, videos, associations, stories, etc.

Each of the texts is presented via the typical questions that are raised in the corresponding situation, since in this way we can anticipate the concerns, or potential concerns, of the patient or family member. In Figure 2, one of the app's screenshots shows a communicative situation with its two corresponding challenges:

\section{[We have a medical test}

\section{What to ask the doctor when she sends my child for a test?}

List of questions we can ask the doctor when she tells us our child needs a test.

\section{How to prepare my child for the tests?}

How to ensure our child is as stress free as possible when taking the medical test.] 
To meet our objectives, members of the patients' families, doctors, scientists, researchers and representatives of rare disease associations have all participated in the development of the application. Thus, in addition to calling on the expertise of all the researchers working on the JUNTS project, we have worked closely with the Spanish Federation of Rare Diseases and with doctors and researchers in the Clinical Genetics Unit of the Hospital Vall d'Hebron, who shared their experiences of having been in the different communicative acts addressed by COMjuntos. And although the vision is multiple (polyphonic), the message and objective are the same: to empower the patient.

In producing the videos - that is, the first level of access to each challenge - we opted for the polyphony of equal voices, so that each situation calls on the experienced voices of doctors, patients and relatives, association representatives, linguists and psychologists. In this way, each situation is always kaleidoscopic, which means we enrich understanding by drawing on the perspectives afforded by others: all are accredited voices albeit with distinct value. All these groups have experiences to relate in order to ensure that communication between families and clinicians is satisfactory.

\section{Treatment of linguistic interferences in COMjuntos}

Thus, COMjuntos can be consulted at different levels and so that each challenge can be addressed at the level of depth desired by the user:

- Level one: visual, by means of videos that introduce each of the communicative challenges.

- Level two: textual, by means of titles, general sections and specific sections that the user can drop down.

- Level three: hypertextual, by means of a dictionary of user terms and information in the form of hyperlinks to carefully evaluated and selected information available on the Internet.

In seeking to reduce linguistic and terminological interferences, we have taken into account the fact that users are not specialists in the health sciences. As such, they are likely to have difficulties in accessing the information transmitted by the professionals, since their cognitive structures in relation to health issues do not coincide. Several studies show that the use of terminology and the abuse of acronyms represent a major communicative barrier in this respect (15) (16). Consequently, one of the issues that requires most management in developing the application is the controlled use of terminology, that is the lexical units of specialized communication which tend to concentrate the most specialized information.

If our goal is to ensure that the language is not an obstacle for the patient (17), it is important to pay careful attention to the words used to speak about health issues and to be sure that they will be understood or, if it is likely they will not be understood, that the means are provided so that communication is not affected. For example, not using a particularly high terminological density in written texts (less than 12\%), explaining unusual lexical units, not using abbreviations without first 
providing their full form, avoiding the use of loan words, etc. are elements that help construct more understandable texts.

In the application designed here, special attention has been paid to the language used. We have sought to control what terminology is used and how it is introduced and explained in the text. Thus, explanatory paraphrases are embedded in the texts, all abbreviations used are given their full expanded form, and specialist terms are hyperlinked to an ad hoc glossary with definitions appropriately worded for the nonspecialist patient. The vocabulary can be accessed directly or through the text's terminological units which have a hyperlink to the glossary (see Figure 3). The texts and the vocabulary have been prepared by the team's researchers and reviewed by linguists, psychologists, doctors and geneticists.

\section{Dissemination via different channels and formats of COMjuntos}

As discussed, the health literacy of the population entails people's knowledge, motivation and competences. The goal is to access, understand, appraise and apply information so that we can play an active role in our health and collaborate with health professionals to increase the quality of life of our children. COMjuntos is an important step forward in helping us achieve these goals. The application has the backing of FEDER, the Spanish Federation that supports patients and family members affected by a rare disease. Thus, the first step to ensuring the success of an application of this type is to facilitate patient access to it.

Since 2018, FEDER has recommended the application to its members via its home page. In this way, as well as certifying the quality of the application, COMjuntos is available to all users of its website. In addition, in 2018 COMjuntos was recognised as the best patient app at the e-Health Awards and this has helped further its dissemination (see Figure 4).

It is also important to ensure that users do not face any technological barriers in accessing information. Therefore, the application has been designed for use in different formats: app, web, print book and downloadable e-book. In addition, all videos are subtitled so that people with hearing difficulties can access the information. Another barrier is often the economic one. CoMjuntos app is free. At the technical level, it was considered that in order to promote knowledge and the use of the application, it should be available, free of charge, in different formats adapted to any type of mobile device. A web version is also available that can be accessed from any internet browser:

https://www.upf.edu/es/web/medicina_comunicacio/app-junts

In addition, there is a print version available for those who prefer to read the materials without using technologies. Finally, this book can also be downloaded in pdf format - the Spanish version being illustrated in Figure 4:

The app is light, occupying only $36 \mathrm{MB}$ of storage space and consuming very few resources of the processor being used. Navigation is highly intuitive. COMjuntos is currently available in both Spanish and Catalan. 


\section{Methods}

JUNTS framework was develop working closely with doctors and patients.

First, we carried out 10 semi-structured interviews with parents of child's affected by a rare disease during 2018. In those interviews we identify a set of categories related to communicative and linguistic barriers in their relationship with the doctors that has treated their kids. In the interviews we are including questions on clinical information, communication experiences with healthcare professionals, and the impact these had on the interviewees' relationships with them. To analyze these interviews, we used the 'grounded theory' framework and open and axial text coding techniques, in addition to those identifying the properties and dimensions of the categories formulated (12) that help researchers to address the COMjuntos contents.

Secondly, we carried out and video recorded interviews with doctors, psychologists, linguistics, parents with children affected by a rare disease and patient's organization staff. The aim of these interviews was to «ask for solutions» to specialists and the patients associations staff.

The third and last steep was to organize a meeting of the whole research team and patient's association staff of Spanish Federation of Rare Disease and list a set of design trends that could help parents to solve the main communicational and linguistic barriers. We summarize the conclusions extracted from three steps in Table 1 where we offer the main design features of JUNTS.

\begin{tabular}{|l|l|}
\hline 1. Design based on patients' needs & Using in-depth interviews \\
\cline { 2 - 2 } & Integrating patients in research team \\
\hline 2. Persuasive design & Applied to the design of the application \\
\cline { 2 - 2 } & Applied to its content \\
\hline \multirow{2}{*}{ 3. Polyphonic and multichannel information design } & Polyphony (many-voiced) \\
\cline { 2 - 2 } & Multichannel \\
\hline \multirow{2}{*}{ 4. Specific treatment of linguistic and cognitive interferences } & By means of linguistic analysis \\
\cline { 2 - 2 } & By means of didactic treatment \\
\cline { 2 - 2 } & By compiling glossaries/dictionaries \\
\hline \multirow{2}{*}{ 5. Dissemination via specific channels } & Patient organisations \\
\cline { 2 - 2 } & Scientific events for patients \\
\cline { 2 - 2 } & Multiformats \\
\hline
\end{tabular}

Table 1.- Characteristics of the JUNTS

In what follows, the five framework principles underpinning JUNTS are outlined

\section{Principle 1: Design centred on patients' needs}

The active participation of patients is essential in the design of any intervention that specifically targets that group and is especially relevant in the case of those affected by a rare disease (5). In our case, the word patient has a metonymic meaning because the app is addressed to the parents of kids affected by a rare disease. In our framework, we employ four strategies specifically to harness patient participation 
as a method for identifying their needs and as an additional means for ensuring their involvement in the project: first, patients are interviewed in-depth; second, two focus groups are set up - in this instance, conducted on FEDER premises; third, a linguistic analysis is made of a corpus of real medical reports with the aim of identifying the factors that impede understanding (12); and, fourth, a survey is carried out comparing patient comprehension of a real report and the same report once it has been enriched linguistically and cognitively

This framework - adopting a user-centred design framework - is inspired by proposals made initially by Witteman (18). The framework, developed in response to evidence that a concept such as patient participation is overly ambiguous and subjective, is based on three elements: understanding the user, developing a prototype and observing how users interact with that prototype.

\section{Principle 2: Persuasive design}

Persuasive design in the field of technological applications has been defined by Fogg (16) as the scientific discipline that studies the characteristics and attributes of technologies, particularly those of the so-called technologies, to support a change in user behaviour, that is, persuading them without resorting to either deception or coercion.

Subsequently, various authors, including Oinas-Kukkonen (17), based on Fogg's assumptions, have developed a complete system for the design and evaluation of online interventions aimed at promoting behavioural change: so-called Persuasive Systems Design (PSD in advance) (17). PSD classifies its design principles as support for carrying out the primary task (e.g. ensuring that the technology is simple and intuitive), support for dialogue (e.g. ensuring that the language is comprehensible and that the system strengthens the user's social role), social support (e.g. ensuring that the user can observe how other people behave in the same situation) and credibility (e.g. ensuring that the system leverages roles of authority to enhance its validity). By applying this model to our app, we can systematically observe how the persuasive system design categories are used and investigate their possible influence on treatment adherence.

\section{Principle 3: polyphonic and multichannel information design}

Health issues are complex problems that can be addressed from very different points of view. Often, however, tools, applications and texts tend to be designed from a single point of view: either that of the doctor (medical report) or that of the patient. Here, by contrast, we argue that diverse voices (polyphony) on the same subject contribute to a richer and more complete perspective of the situation than that offered by any one individual voice.

\section{Principle 4: specific treatment of linguistic and cognitive interferences}

Not all the app's users have the same communicative or information needs. Moreover, not all patients have the same sociocultural level or level of health literacy. For this reason, we propose a design that allows analysis and hermeneutics of the content at a range of levels. 


\section{Principle 5: dissemination via specific channels}

The application is based on the idea that its format should never constitute an obstacle for accessing health information. Sørensen (9) in relation to health literacy considers that:

Health literacy is linked to literacy and entails people's knowledge, motivation and competences to access, [1] understand, appraise, and apply health information in order to make judgments and take decisions in everyday life concerning healthcare, disease prevention and health promotion to maintain or improve quality of life during the life course.

In rare diseases, access to information, as a basic and essential element for improving health literacy (as defined by Sørensen), acquires critical importance. Therefore, we opted to implement the application in multiformats to guarantee the primary necessity of health literacy because the people can actually access the information they need.

[1] The bold is ours.

\section{Discussion}

The JUNTS embodied in COMjuntos has a number of obvious strengths which we have striven to highlight throughout the above presentation and which we summarize below:

1. It is based on real patient needs

2. It employs a persuasive design

3. Knowledge is broken down into four levels of involvement (hermeneutics)

4. Knowledge is transmitted in a polyphonic fashion

5. Professionals are given a voice alongside that of the expert patients

6. The language is highly controlled, especially the use of terminology

7. The information is supported by glossary of the terminology used with explanations tailored for the patient

8. It can be consulted in different formats, both digital and print

9. It is adapted to people with hearing difficulties

10. It is disseminated via patient groups and associations

However, like all applications, COMjuntos is not without features that could be improved. The main limitations of the application are as follows:

1. It is not interactive, which means the patient cannot raise the doubts they have as they consult the application. 
2. It has no robust robot that allows exhaustive monitoring of the user's use of the application.

3. It is very generalist and does not address aspects of a specific rare disease.

4. It is not adapted to blind people and although the videos are subtitled, they are not signed.

5. There is some information that needs to be regularly updated, especially the information regarding data and the fifth of the scenarios: ¿Qué más puedo aprender?(What else can I learn?), since there are constantly new associations being set up or new resources being developed.

6. There are some sections with texts that are too long. Perhaps, they need to be shortened to speed up your understanding.

Additionally, we will expose specific limitations of JUNTS in which is based our app.

The main limitation is that we don't have the opportunity to compare our framework with existing ones. Unfortunally, there exist a lack in evaluation studies about this kind of tools. Generally, the mobile app development professionals don't have in mind a specific framework or framework to address the design. In few word we can't evaluate appropriately COMjuntos until we don't have a framework for assessment including measures such: increase of patient adherences, continuous monitoring of readability and effects in real decisions (e.g. increase the number of parents that ask their doctors after watching comjuntos videos o read specific parts).

\section{Conclusions}

COMjuntos is the first application to use the JUNTS, developed from research into clinician-patient communication from both a linguistic and psychological perspective. We are convinced that the same structure and framework can be applied to other diseases or chronic health conditions with similar benefits. Heras (19) describes how communication between health professionals and patients has been shown to be as important in relieving suffering as the best of painkillers.

COMjuntos has the capacity to transform because, being based on real communicative problems, it provides solutions for the affected population and, moreover, it has a high inclusive potential since it actively and responsibly involves society. As such, it is a good example of knowledge transfer whereby research results are channelled back into society in the form of an application. COMjuntos contributes to changing the level of health literacy in the population and to strengthening the relationship between doctor and patient/family. In this specific case, it helps to empower families with a rare paediatric disease in their communicative relations with the health professionals with whom they collaborate. Now, two years after the application was launched, we are carrying out a survey with actual users in order to have some evidence of its real adequacy and some data that will allow us to improve it.

\section{Abbreviations}


COMjuntos: COMjuntos mobile application

JUNTS: JUNTS framework

FEDER: Federación Española de Enfermedades Raras.

PSD: Persuasive System Design

\section{Declarations}

\section{- Ethics approval and consent to participate}

Our research has been approved by Spanish Federation or Rare Diseases (FEDER) and COMJUNTOS mobile app is nowadays one of the services that FEDER are offering to parents

\section{- Consent for publication}

All the parents and professionals that appear in our videos signed a informed consent about their participation in JUNTS Research Project including the use of the information they provided thorough our Webapp for research purposes.

\section{- Availability of data and material}

Informed consents and original files of COMJUNTOS Project are available by demand

\section{- Competing interests}

We haven't competing interest

\section{- Funding}

the project was funded by Recercaixa (La Caixa) in a competitive call for projects in 2015

\section{- Authors' contributions}

Dra Manuel Armayones wrote first draft. Dra Estopa make reviews and reestructure the text.

Both of us revise the manuscript. Our participation has been equitative in all the paper.

\section{- Acknowledgements}

We want to thank Recercaixa Program (CaixaBank) for funding this project.

In behalf of all the research team we want to thank parents and professionals that participate in COMJUNTOS for their generosity. 
We want to thank Spanish Federation of Rare Diseases (FEDER) for their trust and support in the whole project.

\section{References}

1. Ignatiadis M, Lee M, Jeffrey SS. El paciente crónico. Clin Cancer Res. 2015;

2. Martos Ménde MJ. Enfermedades crónicas y adherencia terapéutica. Enfermedades crónicas y adherencia terapéutica. 2010.

3. Hernández-Clemente JC. La comunicación en la relación médico-paciente. Análisis de la literatura científica entre 1990 y 2010. Revista de Comunicación y Salud. 2014.

4. Coulter A. Patient engagement-what works? J Ambul Care Manage. 2012;

5. Palau F. Determinants for research on rare diseases. Orphanet J Rare Dis [Internet]. 2010 [cited 2015 May 11];5(Suppl 1):016. Available from: http://www.ncbi.nlm.nih.gov/pmc/articles/PMC2958373/

6. Aymé S, Kole A, Groft S. Empowerment of patients: lessons from the rare diseases community. Lancet [Internet]. [cited 2008 Jun 20];371(9629):2048-51. Available from: http://www.sciencedirect.com/science/article/pii/S0140673608608752

7. González-Lamuño Leguina D, García Fuentes M. Enfermedades raras en pediatría. Anales del Sistema Sanitario de Navarra. 2008.

8. Madeo AC, O'Brien KE, Bernhardt BA, Biesecker BB. Factors associated with perceived uncertainty among parents of children with undiagnosed medical conditions. Am J Med Genet Part A [Internet]. 2012 Jan 2 [cited 2013 Jan 2];158A(8):1877-84. Available from: http://onlinelibrary.wiley.com/doi/10.1002/ajmg.a.35425/abstract

9. Sørensen K, Van den Broucke S, Fullam J, Doyle G, Pelikan J, Slonska Z et al. Health literacy and public health: A systematic review and integration of definitions and models. BMC Public Health [Internet]. 2012 Dec 25 [cited 2019 May 1];12(1):80. Available from:

http://bmcpublichealth.biomedcentral.com/articles/10.1186/1471-2458-12-80

10. Spring $\mathrm{H}$. Health information, what happens when there isn't any? Information literacy and the challenges for rare and orphan diseases. Heal Inf Libr J [Internet]. 2014 Sep 1 [cited 2019 May 1];31(3):243-6. Available from: http://doi.wiley.com/10.1111/hir.12068

11. Safeer RS, Keenan J. Health literacy: the gap between physicians and patients. Am Fam Physician [Internet]. 2005 Aug 1 [cited 2015 Jun 23];72(3):463-8. Available from: http://www.ncbi.nlm.nih.gov/pubmed/16100861

12. Gómez-Zúñiga B, Pulido R, Pousada M, García A AM. The Experience of Parents of Children with Rare Diseases When Communicating with Healthcare Professionals: Towards an Integrative Theory of Trust. Orphanet J Rare Dis. 2019;Forthcomin.

13. Oinas-Kukkonen H, Harjumaa M. Persuasive Systems Design: Key Issues, Process Model, and System Features. Commun Assoc Inf Syst [Internet]. 2009 [cited 2019 Mar 23];24:485-500. Available from: https://aisel.aisnet.org/cais/vol24/iss1/28 
14. Armayones, M; García Oliva,A; Gómez Zúñiga,B; Pousada M. Analyzing the Persuasive Design Features in a tool aimed to improve Health Literacy: the case of COMJUNTOS Webapp. In: Ham, J., Karapanos, E., Morita, P., Burns CM, editor. 13th International Conference, PERSUASIVE 2018, Waterloo, ON, Canada, April 18-19, 2018, Proceedings [Internet]. Waterloo (Canadá): Springer; 2018. p. poster presentation. Available from: https://www.springer.com/us/book/9783319789774

15. Borrell F. Entrevista clínica. Manual de estrategias prácticas. semFYC ediciones, editor. Barcelona; 2004.

16. Delàs J. Informes clínics, eines de comunicació. Barcelona: Quaderns de la bona praxis, COMB; 2005.

17. Estopà, R.;Montané M. Terminology in medical reports: textual parameters and their lexical indicators that hinder patient understanding". Amsterdam: Terminology. Amsterdam: Terminology.

18. Witteman HO, Dansokho SC, Colquhoun H, Coulter A, Dugas M, Fagerlin A, et al. User-centered design and the development of patient decision aids: protocol for a systematic review. Syst Rev [Internet]. 2015 Dec 26 [cited 2019 May 25];4(1):11. Available from:

https://systematicreviewsjournal.biomedcentral.com/articles/10.1186/2046-4053-4-11

19. Heras, G. En primera línea. Un testimonio desde la UCI de la crisis del coronavirus. Barceona: Península; 2020.

\section{Figures}




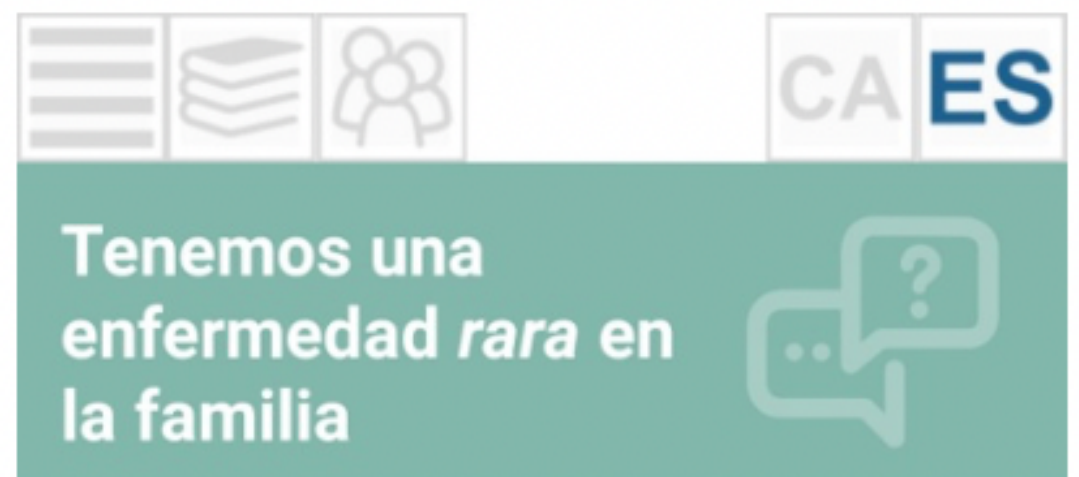

¿Cómo preparar la visita médica?

Recibimos un informe médico

Tenemos una prueba médica
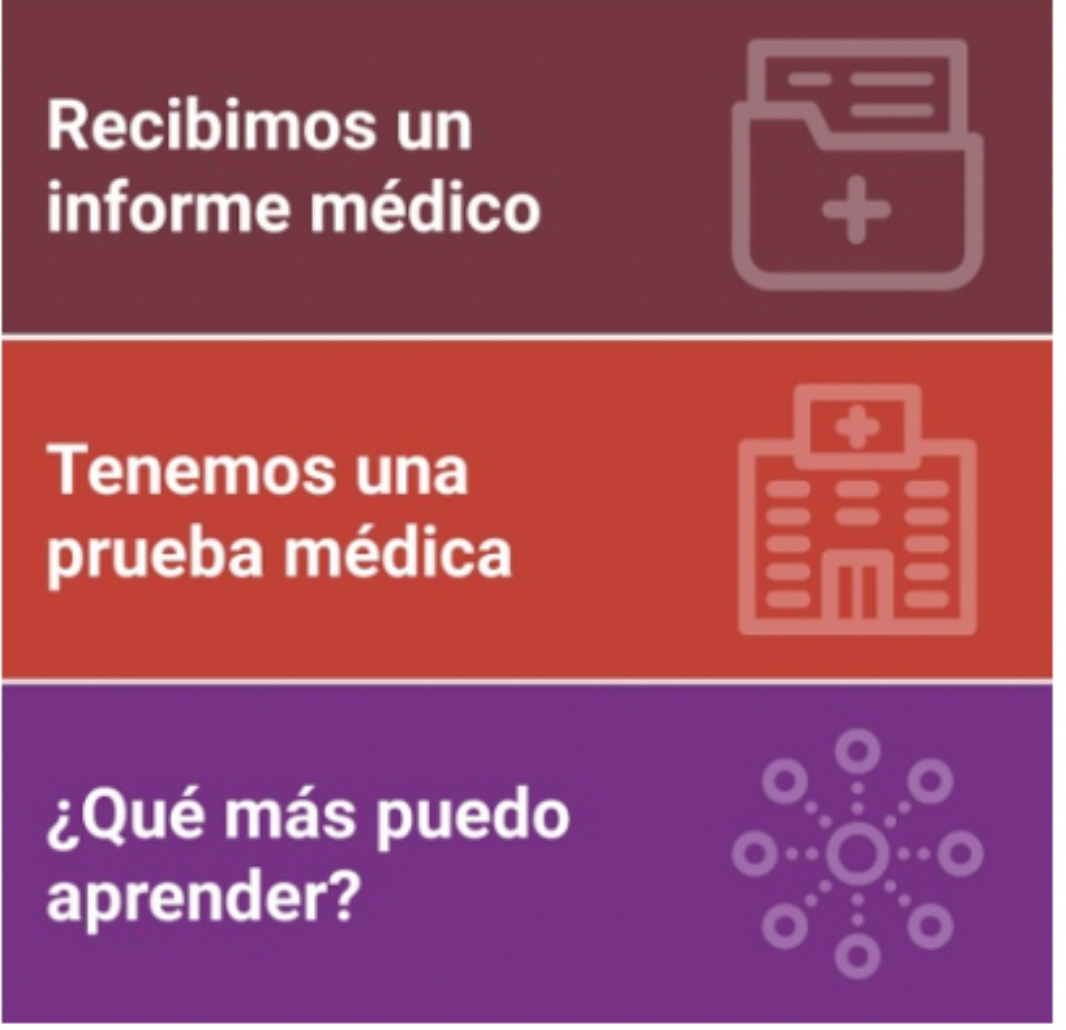

Figure 1

COMjuntos modular structure organised by colours 


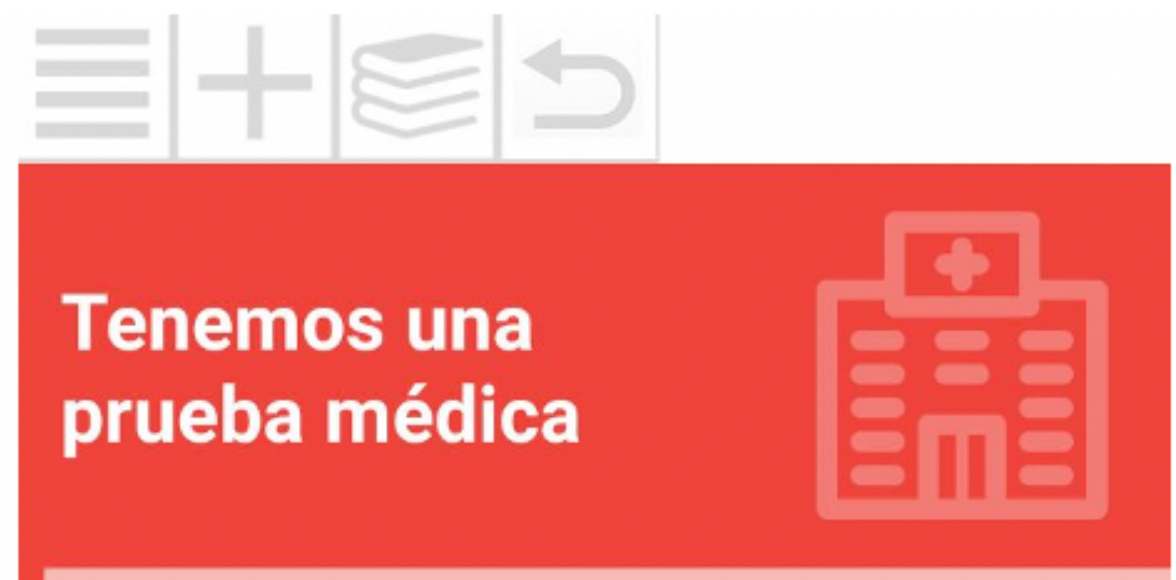

\section{¿Que preguntar a mi médico cuando} prescribe una prueba a mi hijo?

Listado de preguntas que podemos plantearle a nuestro médico cuando nos diga que tenemos que hacerle una prueba a nuestro hijo.

\section{¿Como preparar a mi hijo para las} pruebas?

Cómo hacer que nuestro hijo pase por la prueba médica con el menor estrés posible.

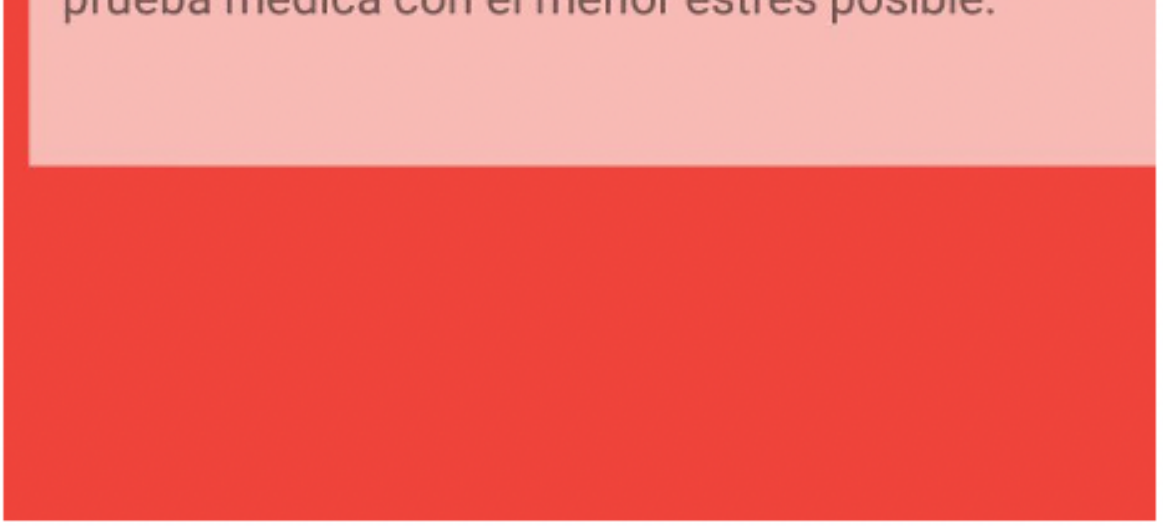

\section{Figure 2}

Screenshot of Challenges 5 and 6 [We have a medical test What to ask the doctor when she sends my child for a test? List of questions we can ask the doctor when she tells us our child needs a test. How to prepare my child for the tests? How to ensure our child is as stress free as possible when taking the medical test.] 


diagnóstico
diagnóstico bioquímico
diagnóstico clínico
diagnóstico de certeza
diagnóstico definitivo
diagnóstico diferencial
diagnóstico genético
diagnóstico molecular
diagnóstico precoz
diagnóstico prenatal
diagnóstico presintomático
E
enfermedad compleja
enfermedad crónica
enfermedad del sistema nervioso
enfermedad dominante
enfermedad endocrina
enfermedad genética
enfermedad genética hereditaria
enfermedad hematológica
enfermedad hereditaria
enfermedad huérfana
enfermedad infecciosa
enfermedad lisosomal

\section{Figure 3}

Screenshot of the application's glossary 


\section{Descarga nuestros contenidos}

\section{App COMjuntos:}
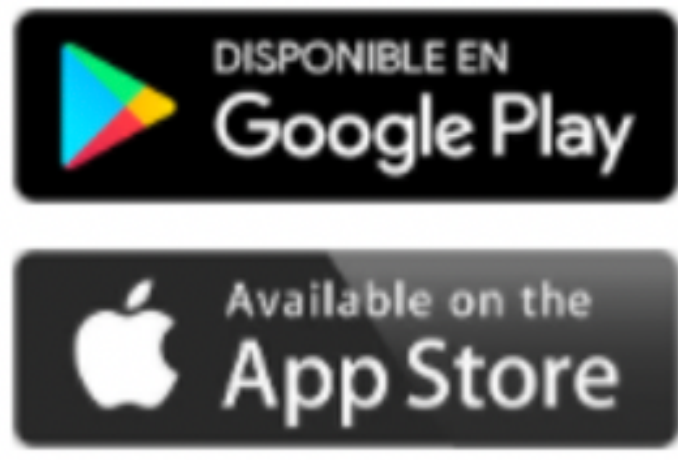

\section{Libro COMjuntos:}

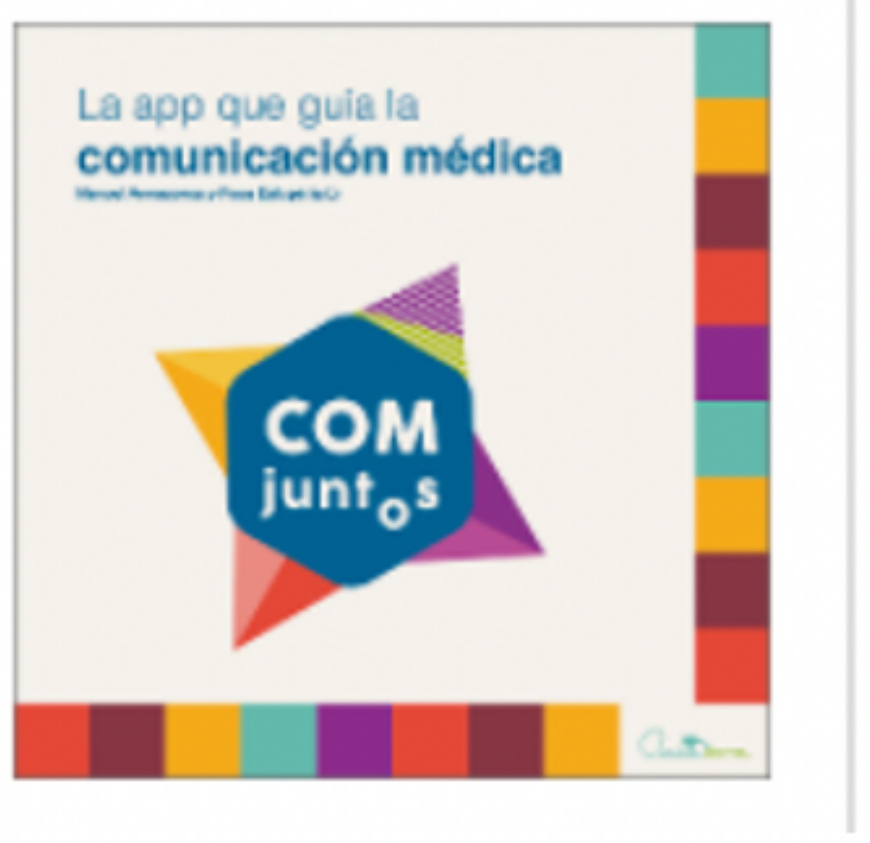

Figure 4

COMjuntos - winner of the eHealth Awards' best app for patients, 2018 